\title{
USE OF THE PAVLIK NAIL FOR FEMORAL SHORTENING
}

\author{
Miroslav Pach*, Miroslav Uvizl, Radomir Holibka
}

\author{
Department of Orthopaedics, Faculty of Medicine and Dentistry, Palacky University and University Hospital, \\ Olomouc, Czech Republic \\ e-mail:pachm@fnol.cz
}

Received: October 10, 2006; Accepted: November 29, 2006

Keywords: Leg length discrepancy (LLD)/Femoral shortening/Osteosynthesis/Pavlik nail/Long-term results/Merle d'Aubigne and Postel score

Background: Selecting the correct type of osteosynthesis has a crucial impact on the final outcome of shortening operations for leg length discrepancy (LLD). One approach, introduced at the beginning of the 1950's, was fixation of femoral shortening osteotomy using the Pavlik intramedullary nail.

Aim: The aim of this paper is to draw attention to the outstanding contribution of this great representative of Czech orthopaedics, to compare his method with other approaches to osteosynthesis, and, in the original patient set, to evaluate the long-term results of femoral shortening based on available medical records.

Material and methods: Of 34 operated patients, a subset of 11 underwent femoral shortening and fixation by the Pavlik nail and were evaluated according to the Merle d'Aubigne and Postel score. Preoperative, postoperative and current radiographs are described.

Results: The results were: excellent (6), good (3), and fair (2). There was no infection, thrombembolism, or osteosynthesis failure. Heterotopic ossification was recorded.

The general validity of Pavlik's technical orthopaedic thinking is confirmed by stable osteosynthesis, and prevalence of excellent and good results.

Conclusion: This study has confirmed the general validity of Pavlik's technical and orthopaedic thinking. His intramedullary nail was a suitable instrument for achieving stable osteosynthesis after a shortening femoral osteotomy. There was neither nail migration nor bone fragment dislocation. No additional plaster immobilization was used and this promoted early, progressive and rapid rehabilitation oriented towards active exercises. The low complication rate was evidence of correct methodology. Despite the undoubted value of the Pavlik femoral intramedullary nail, this method has never become widespread.

\section{INTRODUCTION}

Leg length discrepancy is a general problem worldwide and it has not yet been satisfactorily explained although numerous studies have reported a variety of specific illnesses and disorders leading to leg length discrepancy (LLD) ${ }^{1,2,3}$. Approximately $15 \%$ of the adult population has an LLD greater than $1 \mathrm{~cm}$. Most LLDs $<2 \mathrm{~cm}$ are idiopathic, due to normal anatomic variation in the human body ${ }^{4}$. Such minor discrepancies are generally believed to cause few functional problems. Larger discrepancies typically have demonstrable underlying cause and often require treatment. There are 2 different methods for performing limb shortening: either the epiphyseal growth plate (physis) can be prematurely closed by means of epiphyseodesis, or a long bone can be shortened via bone segment resection. One approach, introduced into treatment at the beginning of the 1950's, was fixation of femoral shortening osteotomy using the Pavlik intramedullary nail. Professor Arnold Pavlik was a reputable Czech orthopaedic surgeon. He was also the originator of the method of intramedullary femoral nailing that involved the construction of a special type of nail, patented in 1959 as No. 89628 and entitled "A double intramedullary expanding nail applicable in orthopaedics and traumatology of the skeleton" 5 .

The aims of this paper are:

- to draw attention to the outstanding contribution of this great representative of Czech orthopaedics

- based on comparison of the Pavlik nail with other osteosynthesis types, and based on the evaluation of long-term results of the original patient set, to answer the question whether osteotomy fixation using the Pavlik nail may be considered a stable osteosynthesis

\section{MATERIAL AND METHODS}

The nail was used from 1954 to 1960 in 34 patients (13 males and 21 females) after femoral shortening for various indications involving defects of the other limb (Tab. 1). Considerable effort was made to locate as many of the 34 patients operated on over the years 1954 to 1960 as possible by searching the birth and death registers as 
well as through insurance companies. Only 15 came for follow-up in 2004. The rest were either dead or ignored our invitation. Of the 15 , a further 4 were excluded due to incomplete medical records. The group thus contained 11 patients, 5 males and 6 females representing $32 \%$ of the total 34 post-surgical patients. The mean age of patients at the time of osteotomy was 18.1 years (range, 16-22), standard deviation of 2.4. The mean age at the time of follow up was 65.8 years (range, 63-70), standard deviation was 2.4. The length of the observation period was thus 47.7 years on average (range, 46-50).

\section{Description of the nail}

The Pavlik nail was made of stainless steel (Poldi anticorro AKVS, Fig. 1) and consisted of two parts, an outer and a central nail (Fig. 2). The outer nail comprised a tube with an enlarged hollow cylindrical head which was longitudinally grooved and had screw threads on its inner surface. The lower end of the outer nail shaft was divided into two jaws of either short or long type. At the upper end of the jaws there were 2 holes to prevent splitting of the tube during central nail insertion. The central nail was $1 \mathrm{~mm}$ shorter than the outer nail to enable jaw opening during tightening. Thus the whole nail was fixed in the femur diaphysis which prevented any rotational or longitudinal movement as well as migration of the nail in the proximal direction. About one-half of the outer nail head length, preferably three quarters, had to be inserted within the spongiosa of the greater trochanter to secure proximal fragment stability. In addition, Pavlik also designed his own special instruments, which unfortunately were not preserved. A depiction may be seen in Pavlík's original paper from 1957(ref. ${ }^{5}$ ).

\section{Surgical technique}

The surgery involved a lateral approach to the greater trochanter and this was extended distally during femoral shortening. An osteotomy was then carried out 0-3 cm below the lesser trochanter level using a Gigli saw, a reciprocal electric saw, or by means of an osteotome. This was followed by necessary bone resection and extension of the medullar cavity, first the proximal and then the

Table 1. A list of diagnoses made before surgery.

\begin{tabular}{|l|c|c|}
\hline Shortening as a result of & $\mathrm{n}$ & $\%$ \\
\hline Coxitis & 10 & 29.4 \\
\hline Poliomyelitis & 7 & 20.6 \\
\hline Osteomyelitis & 5 & 14.7 \\
\hline Femoral bifurcation & 1 & 2.9 \\
\hline DDH & 3 & 8.8 \\
\hline Femoral fracture & 5 & 14.7 \\
\hline Limb hemihypolplasia & 3 & 8.8 \\
\hline Total & 34 & 100.0 \\
\hline
\end{tabular}

DDH - Developmental dislocation of the hip distal fragment. The next step was the preparation of the bed for the outer nail head. For this purpose, the distal and the proximal ends of both fragments were shaped by means of reamers to become convex and concave, respectively. After reduction, the outer nail was first inserted into the prepared cavity. This was followed by the central nail which was firmly tightened. Finally, periosteal fixation was performed using deep stitching, and the wound was closed in the usual fashion.

\section{Postoperative treatment}

The limb was placed in a Braun splint without further immobilization, and a programme of active rehabilitation was begun as soon as possible. Thus, 5-7 days after surgery the patients were verticalized and walking on crutches. They were allowed to place their full weight on the operated limbs by the end of the first week and/or during the second week after surgery. In most cases there was no physiotherapy, massage or passive exercise. The metal parts were removed on average 10 months (range, 7-13) after the shortening osteotomy.

\section{Evaluation}

The evaluation was made according to the Merle d'Aubigne and Postel scores (Tab. 2 and 3$)^{6,7}$. We described pain, mobility and ability to walk. We also evaluated preoperative, postoperative , and current radiographs.

\section{RESULTS}

From the medical records, the mean shortening length was $5.5 \mathrm{~cm}$ (range, 4-9) and the nail diameter was $10 \mathrm{~mm}$ in nine cases and $12 \mathrm{~mm}$ in two cases. On average the surgery lasted 75 minutes. A list of the diagnoses of the patient sample before surgery and at check-up is given in Tables 1 and 4, respectively. Table 5 shows the results after evaluation according to the Merle d'Aubigne and Postel scores. When describing the radiographs we discovered an early formation of periostal, followed by endostal, callus, beginning on the medial aspect of the femur (Fig. 3).

There was no evidence of infection, thrombembolism, nonunion or osteosynthesis failure due to nail

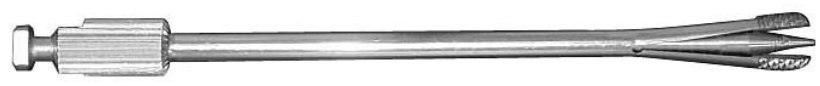

Fig. 1. A complete Pavlik nail. Inner nail is inserted into the outer part with open jaws.

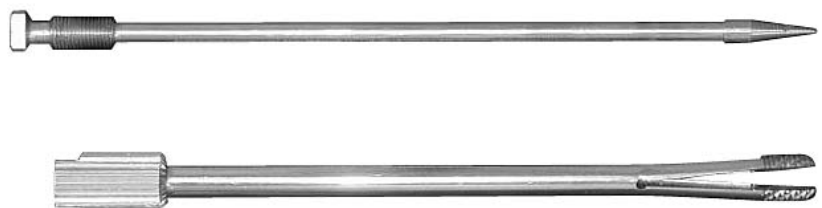

Fig. 2. Parts of the Pavlik nail (central and outer nail). 
Table 2. Merle d'Aubigne and Postel scores - Method of grading functional value of hip.

\begin{tabular}{|c|l|l|l|}
\hline Points & \multicolumn{1}{|c|}{ Pain } & \multicolumn{1}{|c|}{ Mobility } & \multicolumn{1}{|c|}{ Ability to walk } \\
\hline 0 & Pain is intense and permanent. & $\begin{array}{l}\text { Ankylosis with bad position } \\
\text { of the hip. }\end{array}$ & None. \\
\hline 1 & Pain is severe even at night. & $\begin{array}{l}\text { No movement; pain or slight } \\
\text { deformity. }\end{array}$ & Only with crutches. \\
\hline 2 & $\begin{array}{l}\text { Pain is severe when walking; } \\
\text { prevents any activity. }\end{array}$ & Flexion under $40^{\circ}$. & Only with canes. \\
\hline 3 & $\begin{array}{l}\text { Pain is tolerable with limited } \\
\text { activity. }\end{array}$ & $\begin{array}{l}\text { Flexion between } 40^{\circ} \text { and } 60^{\circ} . \\
\text { disappears with rest. }\end{array}$ & $\begin{array}{l}\text { With one cane, less than one hour; } \\
\text { very difficult without a cane. }\end{array}$ \\
\hline 5 & $\begin{array}{l}\text { Pain is mild and inconstant; } \\
\text { normal activity. }\end{array}$ & $\begin{array}{l}\text { Flexion between } 60^{\circ} \text { and } 80^{\circ} ; \\
\text { patient can reach his foot. } \\
\text { abduction of at least } 15^{\circ} .\end{array}$ & $\begin{array}{l}\text { A long time with a cane; short time } \\
\text { without cane and with limp. }\end{array}$ \\
\hline 6 & \begin{tabular}{l} 
No pain. \\
\hline
\end{tabular} & $\begin{array}{l}\text { Flexion of more than } 90^{\circ} ; \\
\text { abduction to } 30^{\circ} .\end{array}$ & Without cane but with slight limp. \\
\hline
\end{tabular}

Table 3. Merle d'Aubigne and Postel scores Functional grading of the hip.

\begin{tabular}{|c|c|}
\hline Result & Points \\
\hline Excellent & $17-18$ \\
\hline Good & $12-16$ \\
\hline Fair & $6-11$ \\
\hline Unsatisfactory & $0-5$ \\
\hline
\end{tabular}

migration, bending, breakage, and/or fragment dislocation. Heterotopic ossification was observed in 3 cases (Fig. 4).

\section{DISCUSSION}

Leg length discrepancy is a general problem worldwide and it has not yet been satisfactorily explained although numerous studies have reported a variety of specific illnesses and disorders leading to leg length discrepancy ${ }^{1,2,3}$. These include congenital anomalies, developmental and tumorous changes to the skeleton, soft tissue malformations, infections and inflammatory states affecting growth plates, venous supply to the epiphysis or metaphysis, trauma, neuromuscular disorders and other conditions like coxa vara in adolescents, Legg-Calvé-Perthes disease, prolonged immobilization inside ortheses, radiation therapy and closure of the physis ${ }^{8}$. The problem can be resolved by surgical intervention for limb shortening and/
Table 4. Diagnoses of patients who underwent check-up.

\begin{tabular}{|l|l|l|}
\hline Shortening as a result of & $\mathrm{n}$ & $\%$ \\
\hline Coxitis & 4 & 36.4 \\
\hline Poliomyelitis & 3 & 27.3 \\
\hline DDH & 2 & 18.2 \\
\hline Femoral fracture & 1 & 9.1 \\
\hline Limb hemihypolplasia & 1 & 9.1 \\
\hline Total & 11 & 100.0 \\
\hline
\end{tabular}

DDH - Developmental dislocation of the hip

Table 5. Evaluation of results according to the Merle d'Aubigne and Postel scores.

\begin{tabular}{|l|c|c|}
\hline Result & $\mathrm{n}$ & $\%$ \\
\hline Excellent (17-18) & 6 & 54.5 \\
\hline Good (12-16) & 3 & 27.3 \\
\hline Fair (6-11) & 2 & 18.2 \\
\hline Unsatisfactory $(0-5)$ & 0 & 0 \\
\hline Total & 11 & 100.0 \\
\hline
\end{tabular}

or lengthening ${ }^{9,10}$. At present, there are 2 different methods for performing limb shortening: either the epiphyseal growth plate (physis) can be prematurely closed by means of epiphyseodesis, or a long bone can be shortened via bone segment resection.

Epiphyseodesis was first described by Phemister in 1933 to manage the leg length discrepancies ranging from 2 to $5 \mathrm{~cm}\left(\right.$ ref. $\left.^{11}\right)$. The shortening osteotomy, however, is appropriate for patients who are not candidates for limb 

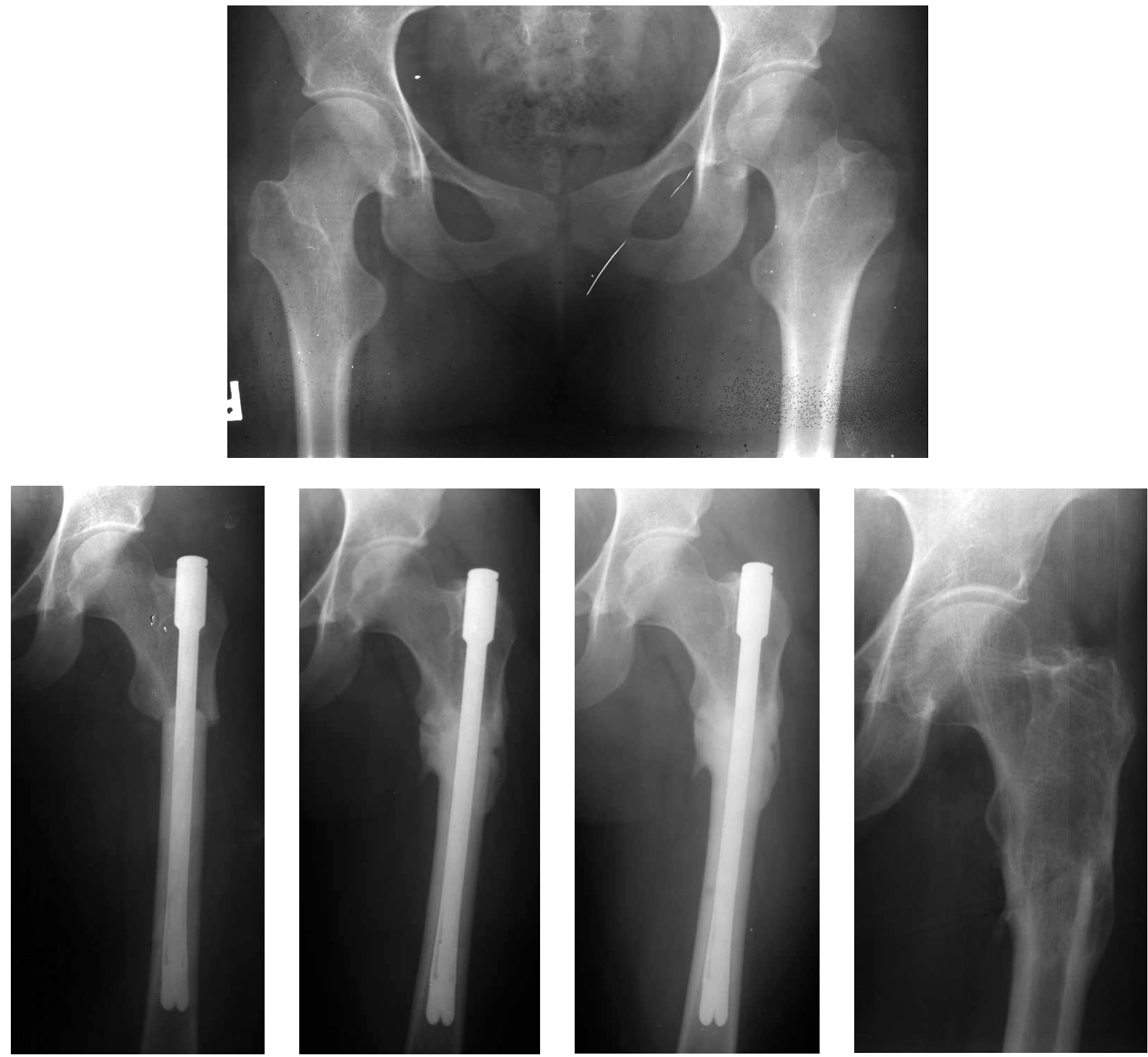

Fig. 3. a. A 17 year-old patient, after poliomyelitis at the age of 1.5 years, a right-sided disorder. A preoperative radiograph.

b. A postoperative radiograph after shortening subtrochanteric osteotomy with osteosynthesis using the Pavlik nail - a correct position.

c. 6 months post operation, healed osteotomy.

d. 12 months post operation.

e. 45 years post operation, physiological range of motion.

lengthening, do not wish to undergo this intervention, or are too old for epiphyseodesis. Nonetheless, experience has shown that the femur is more suitable for shortening than the tibia ${ }^{1}$.

Rizzoli was the first to describe the correction of limb length discrepancies using the shortening osteotomy in Bologna (Italy) in 1847 when he resected part of the femur on a healthy limb ${ }^{12}$. The shortening femoral osteotomy can be performed in three different areas: the proximal femur using splint fixation, DHS or an intramedullary nail, diaphysis using fixation with a locked intrameduallary nail, and finally distal femur fixated with an angular splint or an intramedullary nail. The above methods are very precise and permit a remarkably shorter recovery period in contrast to elongation procedures ${ }^{13,14}$, but they require another smaller intervention to remove the implant.

Lambotte was the first to report the use of intramedullary nailing in $1907\left(\right.$ ref $^{15}$ ) followed by Küntscher in 1939 who designed and improved the nail ${ }^{16}$, but neither of these designs was completely acceptable. Sooner or later the nail started to loosen, particularly in the femoral area, and migrated proximally. There were additional problems such as rotational instability of the fragments and fragment distraction after osteosynthesis, after bone resection of tumours, or after shortening surgery. In gen- 
eral, the intramedullary nails always had a tendency to bend and break $^{17}$. A disadvantage of some other methods used for the shortening osteotomies was the need for long post-surgical immobilization, sometimes lasting several months, in a plaster cast ${ }^{18}$. In an effort to overcome these problems, Pavlik designed and introduced his own femoral intramedullary nail in 1954. This guaranteed fragment stability based on precise insertion ${ }^{5}$. The stability achieved was comparable with the currently used locked nailing ${ }^{19,20}$, making it possible to start a progressive rehabilitation programme during the first or second postoperative week.

Patients were allowed to start walking on crutches on the $5^{\text {th }}-7^{\text {th }}$ day after surgery. This was made possible by detailed and sophisticated shaping of the osteotomized surfaces. The patient records contained ample information regarding postoperative conditions. One reported climbing a ladder in the 3rd postoperative week, another was able to jump rope and dance in the $5^{\text {th }}$ week after surgery. Excellent results according to the Merle d'Aubigne and Postel scores and a remarkably low rate of complications were due to the introduction of a rehabilitation programme with active exercises, early verticalization, and above all as a result of the nail design and thorough elaboration of the individual stages of the surgical procedure. At present, a subtrochanteric shortening osteotomy is followed by fixation with locked intramedullary nailing either proximally or on both nail ends . Some authors, however, have reported various complications such as functional disorders of the quadriceps muscle, hamstring, and nonunion ${ }^{21,22}$. There may be instability, telescopic and rotational deformities, and reduced muscular function after a shortening osteotomy in the femoral diaphysis with fixation by means of locked nailing. It is recommended that the fixation is improved using a short splint ${ }^{23}$.

\section{CONCLUSION}

This study has confirmed the general validity of Pavlik's technical and orthopaedic thinking, first demonstrated by his designed harness for treating congenital hip dislocations. His intramedullary nail was a suitable instrument for achieving stable osteosynthesis after a shortening femoral osteotomy. There was neither nail migration nor bone fragment dislocation. No additional plaster immobilization was used and this promoted early, progressive and rapid rehabilitation oriented towards active exercises. A low complication rate was evidence of correct methodology. Despite the undoubted value of the Pavlik femoral intramedullary nail, this method has never become widespread. Unfortunately, after his death in 1962, it received no opportunity for further development, not even at the originator's orthopaedic department, and these days, it is no longer used. Currently, there is a large number of stabilising osteosynthesis systems at our disposal, that deal with the task of stable fixation after shortening osteotomies. The Pavlik nail, however, is a technique worth knowing about, and shows Pavlik's timeless thinking.
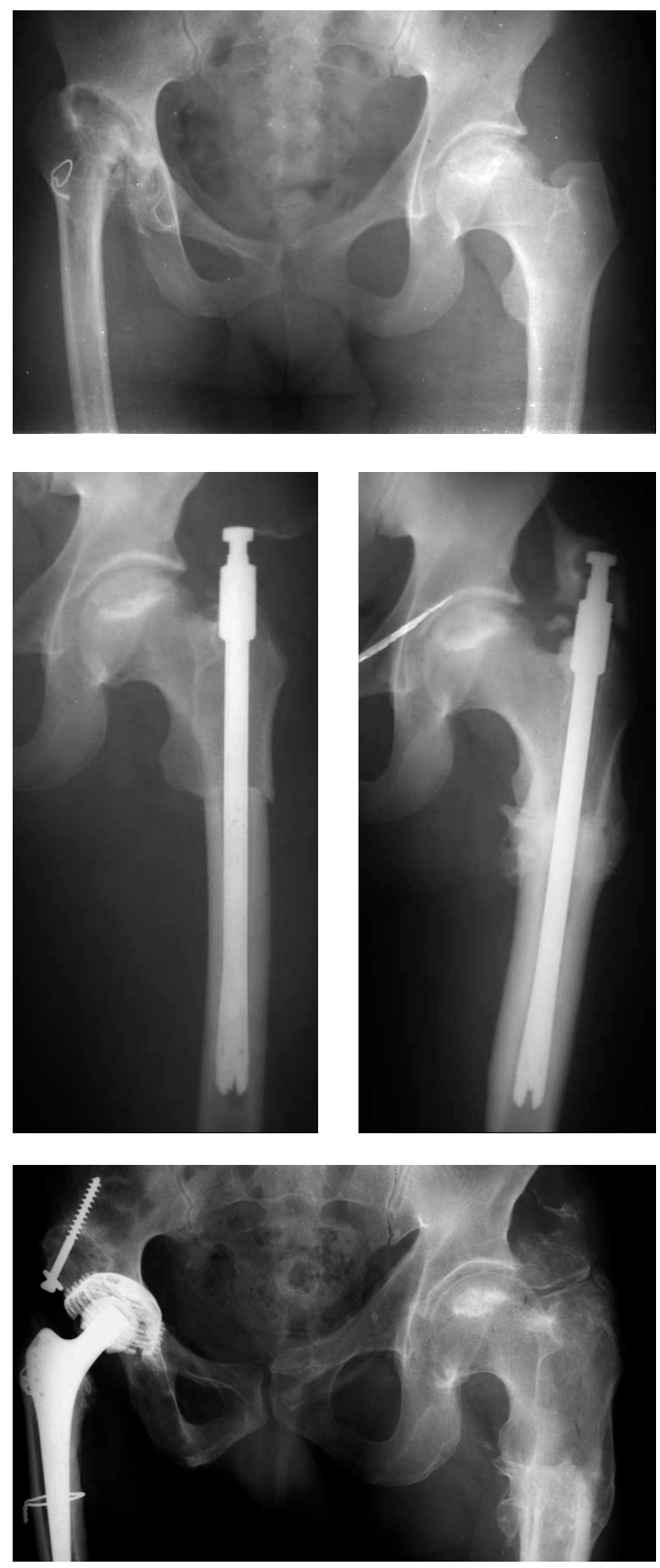

Fig. 4. a. A 21 year-old patient, a preoperative radiograph, on the right - shortening as a result of DDH.

b. A postoperative radiograph after femoral shortening with osteosynthesis using the Pavlik nail - incorrect insertion of the outer nail, excessive length of the central part.

c. 10 months post operation, osteotomy healed, calcification around the nail head.

d. 47 years post operation with some heterotopic ossification and THR of the right postdysplastic hip. Range of motion: S 0-0-110 F 10-0-20 R 20-0-10. 


\section{ABBREVIATIONS}

LLD - Leg length discrepancy

DDH - Developmental dislocation of the hip

THR - Total hip replacement

\section{ACKNOWLEDGMENTS}

The authors wish to thank Ms. J. Potomková and Dr. A. Oulton for their assistance in preparation of the manuscript.

\section{REFERENCES}

1. Codivilla A. On the means of lengthening in the lower limbs, the muscles and tissues which are shortened through deformity. Am J Orthop Surg 1905; 2:353-369.

2. Shapiro F. Developmental patterns of lower extremity discrepancies. J Bone Joint Surg Am 1982; 64:639-651.

3. Torode I P. The behavior of limb inequality in specific disorders. In: Menelaus MB, ed. The management of limb inequality. London: Churchill - Livingstone; 1991. p. 37-38.

4. Stricker SJ, Hunt T. Evaluation of leg length discrepancy in children. Int Pediatr 2004; 19:134-142.

5. Pavlík A. A femoral intramedullary nail. J Bone Joint Surg Am 1957; 39:1059-1075

6. Merle d'Aubigne R. Cotation chiffrée de la function de la hanche. Rev Orthop 1970; 56:481-486.

7. Merle d'Aubigne R, Postel M. Functional results of hip arthroplasty with acrylic prosthesis. J Bone Joint Surg 1954; 34A: 451-475.

8. Tachdjian M O. Pediatric Orthopedics. Philadelphia, USA: W.B Saunders Company, 1990
9. Siffert RS. Current concepts review: lower limb-length discrepancy. J Bone Joint Surg Am 1987; 69:1100-1106.

10. Wagner H. Surgical lengthening or shortening of femur and tibia. Technique and indications. Progress in Orthop Surg 1977; 1:7194.

11. Phemister DB. Operative arrest of longitudinal growth of bones in treatment of deformities. J Bone Joint Surg 1933; 15:1-15.

12. Stamp WG and Lansche WE. Treatment of discrepancy in leg length. South Med J 1960; 53:764-774.

13. Blair VP 3rd, Schoenecker PL, Sheridan JJ, Capelli AM. Closed shortening of the femur. J Bone Joint Surg Am 1989; 71:14401447.

14. Chapman ME, Duwelius PJ, Bray TJ and Gordon JE. Closed intramedullary femoral osteotomy, shortening and derotation procedures. Clin Orthop 1993; 287:245-251.

15. Lambotte A. L'intervention opératoire dans les fractures récentes et anciennes envisagée particulierement au point de vue de l'osteo synthése avec la description de plusieurs techniques nouvelles. Paris: A. Kaloune, 1907.

16. Küntscher G. Die Marknagelung. Berlin: Verlag Dr. Werner Saenger, 1950

17. Thompson TC, Straub LR and Campbell RD. An evaluation of femoral shortening with intramedullary nailing. J Bone Joint Surg Am 1954; 36:43-56.

18. Zahradníček J. Chirurgické léčení nestejně dlouhých dolních končetin. Čas lék čes 1943; 48:1407.

19. Kempf I, Grosse A, Abalo C. Locked intramedullary nailing: its application to femoral and tibial axial, rotational, lengthening and shorthening osteotomies. Clin Orthop 1986; 212:165-173.

20. Kenwright J. Shortening by bone resection. Seminars in Orthopaedics 1992, 7(3):194-200.

21. Čech O, Stryhal F, Sosna A, Beznoska S. Stabilní osteosyntéza v traumatologii a ortopedii. Praha: Avicenum, 1982.

22. Kenwright J, Albinana J. Problems encountered in leg shortening. J Bone Joint Surg Br 1991; 73:671-675.

23. Bianco AJ. Femoral shortening. Clin Orthop 1978; 136:49-53. 